\title{
Synthesis and Performance of (E)-3-Phenyl-2-(thiophen-2-yl) acrylonitrile-Based Small-Molecule Semiconductors
}

\author{
Dizao $\mathbf{L i}^{\mathbf{a}(\mathbb{D})}$ \\ Qiang Wang ${ }^{\text {b }}$ \\ Liping Wang*b \\ Weifeng Zhang ${ }^{a}$ \\ Gui Yu*a,c (D) \\ ${ }^{a}$ Beijing National Laboratory for Molecular Sciences, CAS Research/Education Center \\ for Excellence in Molecular Sciences, Institute of Chemistry, Chinese Academy of \\ Sciences, Beijing, P. R. China \\ yugui@iccas.ac.cn \\ ${ }^{\mathrm{b}}$ School of Materials Science and Engineering, University of Science and Technology \\ Beijing, Beijing, P. R. China \\ lpwang@mater.ustb.edu.cn \\ School of Chemical Sciences, University of Chinese Academy of Sciences, \\ Beijing, P. R. China
}

Received: 20.08.2019

Accepted after revision: 08.11.2019

DOI: 10.1055/s-0039-3402057; Art ID: om-19-0008-oa

License terms: (c)

(c) 2019. The Author(s). This is an open access article published by Thieme under the terms of the Creative Commons Attribution-NonDerivative-NonCommercial-License, permitting copying and reproduction so long as the original work is given appropriate credit. Contents may not be used for commercial purposes, or adapted, remixed, transformed or built upon. (https://creativecommons.org/licenses/by-nc-nd/4.0/).

Abstract Based on diketopyrrolopyrrole (DPP) and (E)-3-phenyl-2(thiophen-2-yl)acrylonitrile (BVCNT)-linked conjugated backbones, three donor-acceptor type conjugated organic small-molecule compounds DPP-BVCNT, DPP-2FBVCNT, and DPP-3FBVCNT were designed and synthesized. Among them, the 2-decyltetradecyl side chain on the DPP acceptor unit was used to ensure the solubility of the material. The fluorine $(F)$ atoms combined with the nitrile on the BVCNT donor unit were used to adjust electronic structures and charge carrier transport properties of the conjugated system. All the three small molecules exhibited good solution dispersibility and thermal stability, providing an important guarantee for the solution processing and annealing optimization of organic field-effect transistors (OFETs). The top-gatebottom-contact OFET devices based on these compounds showed good ambipolar or p-type performances. The relationship between molecular structures and OFET performances indicated that the F-substitution and its position significantly affected their charge carrier transport properties. The F-substitution could remarkably change the performance from $\mathrm{p}$-type to ambipolar especially for the outer-side-Fsubstituted compound DPP-2FBVCNT, which showed the best OFET performances with the maximum hole/electron mobilities of $0.023 / 0.220 \mathrm{~cm}^{2} \mathrm{~V}^{-1} \mathrm{~s}^{-1}$. These results provided a promising idea for developing small-molecule OFET materials with good solution processability, good thermal stability, and high ambipolar performances.

Key words small-molecule semiconductors, organic field-effect transistors, mobility

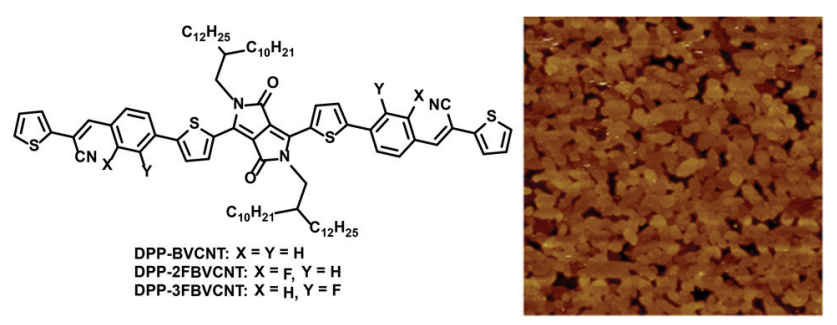

\section{Introduction}

It is well known that ambipolar organic compound semiconductors are important for the fabrication of complementary circuits. ${ }^{1-3}$ Compared to conjugated polymers, organic conjugated small-molecule semiconducting materials have advantages such as structure determination, purity, and solubility control, which are of great significance for the fabrication of organic field-effect transistors (OFETs). ${ }^{4,5}$ Molecular engineering including side-chain engineering and molecular backbone modification is currently a commonly used method for obtaining high-mobility OFET materials. ${ }^{6-11}$ In this research work, the molecular engineering method was fully utilized. A branched alkyl chain (2-decyltetradecyl chain) with a suitable length and spatial orientation was used as the side chain on the diketopyrrolopyrrole (DPP) acceptor unit to ensure the basic solubility of the material. (E)-3-Phenyl-2(thiophen-2-yl) acrylonitrile (BVCNT) having a good planarity and an electron-withdrawing nitrile $(\mathrm{CN})$ group was used as a donor unit. By adjusting the substitution and its position of another type of electron-withdrawing group (fluorine $\mathrm{F}$ ) on the donor units, we obtained a series of donor-acceptor (D-A) type $\pi$-conjugated organic small molecules as ambipolar or p-type OFET materials with a good comprehensive performance. Based on the above considerations, we designed and synthesized three $\mathrm{D}-\mathrm{A}$ type $\pi$-conjugated organic smallmolecule compounds DPP-BVCNT, DPP-2FBVCNT, and DPP3FBVCNT containing the DPP and BVCNT units. Their thermal properties, optical characteristics, electrochemical properties, the films' microscopic arrangement, surface morphology, and charge carrier transport properties were systematically studied. All these three conjugated compounds exhibited good thermal stability and good solution processability, providing an important guarantee for the processing and performance optimization of their OFET devices. Based on these $\pi$-conjugated compounds, we fabricated OFET devices with top-gate bottom-contact (TGBC) configurations, which 
showed good ambipolar or p-type charge carrier-transporting performances. Among them, the introduction and substitution position of $\mathrm{F}$ atoms on the BVCNT units in the D-A conjugated backbones had significant influences on the charge-carrier transport properties of the conjugated organic small molecules.

\section{Results and Discussion}

\section{Synthesis and Thermal Properties}

In order to obtain the key intermediates $\mathbf{2 a - 2 c}$, we used the Knoevenagel condensation reaction method reported in the literature. ${ }^{19}$ The intermediate compound $\mathbf{3}$ was prepared by using lithium diisopropylamide (LDA) and pinacol borate according to the literature. ${ }^{12-18}$ Finally, the key intermediates $\mathbf{2 a - 2 c}$ were respectively coupled with compound 3 using the Suzuki coupling method with the catalyst $\mathrm{Pd}\left(\mathrm{PPh}_{3}\right)_{4}$ to prepare the three target conjugated compounds DPP-BVCNT, DPP-2FBVCNT, and DPP-3FBVCNT. The synthetic routes of the target conjugated compounds and intermediates are shown in Scheme 1. The final products were structurally confirmed by nuclear magnetic resonance (NMR) and high-resolution mass spectrometry (HRMS). At the same time, in order to ensure the feasibility of annealing in subsequent OFET device processing to optimize charge carrier transport performance, the good thermal stability of these compounds is necessary. It is considered that thermogravimetric analysis (TGA) can usually be used to detect the thermal properties of organic semiconductor materials. ${ }^{20}$ We performed the TGA of these conjugated compounds to detect their thermal properties. The TGA results of these conjugated compounds are shown in Figure S1 and the corresponding data are listed in Table 1. According to the TGA data, the three conjugated compounds DPP-BVCNT, DPP-2FBVCNT, and DPP-3FBVCNT showed their $5 \%$ weight loss at $401.6,407.3$, and $409.6{ }^{\circ} \mathrm{C}$, respectively. These temperature data indicated that the degradation temperatures of these three conjugated organic small-molecule compounds were all above $400^{\circ}$ $\mathrm{C}$, and thus these organic compounds showed good thermal stability. This provides a good stability guarantee for the optimization of annealing in the preparation of corresponding OFET devices.

\section{Optical Properties}

The photophysical properties of the three DPP-DBVCNTbased conjugated compounds DPP-BVCNT, DPP-2FBVCNT, and DPP-3FBVCNT were measured by using UV-Vis-NIR

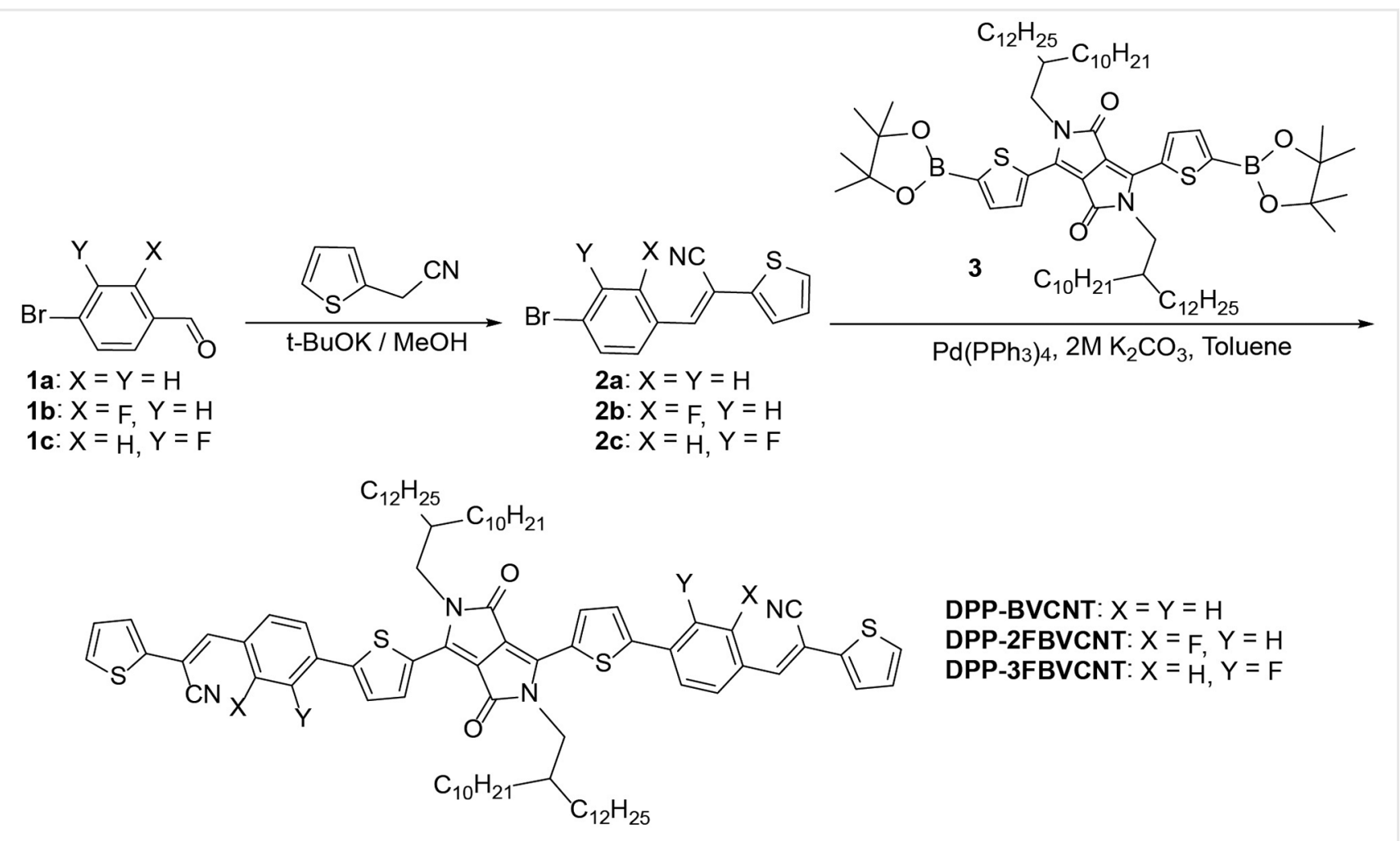

Scheme 1 Synthetic routes of DPP-BVCNT-based compounds. 
Table 1 Thermal, optical, and electrochemical properties of small molecules based on DPP-DBVCNT

\begin{tabular}{llllllll}
\hline Compd & $\left.T_{\mathrm{d}}{ }^{\mathrm{a}}{ }^{\circ} \mathrm{C}\right)$ & $\lambda_{\max }{ }^{\mathrm{b}}($ solution) $(\mathrm{nm})$ & $\lambda_{\max }{ }^{\mathrm{b}}(\mathrm{film})(\mathrm{nm})$ & $E_{\mathrm{g}}(\mathrm{opt})^{\mathrm{c}}(\mathrm{eV})$ & $E_{\text {HOMO }}(\mathrm{eV})$ & $E_{\mathrm{LUMO}}(\mathrm{eV})$ & $E_{\mathrm{g}(\mathrm{ec})}{ }^{\mathrm{d}}(\mathrm{eV})$ \\
\hline DPP-BVCNT & 401.6 & 595 & 711 & 1.58 & -5.51 & -3.67 & 1.84 \\
DPP-2FBVCNT & 407.3 & 596 & 713 & 1.59 & -5.68 & -3.69 & 1.99 \\
DPP-3FBVCNT & 409.6 & 595 & 694 & 1.60 & -5.67 & -3.67 & 2.00 \\
\hline
\end{tabular}

a Temperature at $5 \%$ weight loss.

${ }^{\mathrm{b}}$ Maximum absorption wavelengths in chloroform solution and film state.

cCalculated according to the wavelength at the peak onset in the UV-Vis-NIR absorption spectra in the film state.

${ }^{\mathrm{d}}$ Estimated from the HOMO and LUMO energy levels.

spectroscopy. The UV-Vis-NIR absorption spectra of these three compounds in chloroform solutions (concentration $10^{-5} \mathrm{M}$ ) and thin films are shown in Figures 1 and S2.

From the UV-Vis-NIR absorption spectra, we found that in the chloroform solutions (Figure S2a), the maximum absorption wavelengths of DPP-BVCNT, DPP2FBVCNT, and DPP-3FBVCNT were 595, 596, and $595 \mathrm{~nm}$, respectively, with almost no significant difference. In the films (Figure S2b), the maximum absorption wavelengths of DPP-BVCNT, DPP-2FBVCNT, and DPP-3FBVCNT were 711, 713, and $694 \mathrm{~nm}$, respectively, also without significant difference. However, by comparing the absorption in solution and films of each material (as shown in Figure 1a-c), we found two differences. One difference was that the corresponding absorption peak of the maximum absorption wavelength in solution was found to be close to the Gaussian distribution, while in films it exhibited obvious shoulder peaks showing a clear aggregation effect. The other difference was that the maximum absorption wavelength of the thin film showed a red-shift of about $100 \mathrm{~nm}(99-117 \mathrm{~nm})$ compared to that of the respective solution. It can be seen that the aggregation effect of each organic small-molecule material in the film is much higher than that in the corresponding solution. It can be also reflected from the side angle that there was a high degree of dispersion for this series of materials in the chloroform solution. And there was almost no preaggregation phenomenon for these three materials in solution, which should be beneficial for the processing of corresponding OFET devices by the solution method. The peak shapes of the absorption peaks at the maximum absorption wavelengths of the three materials were almost identical for each both in the solution and film state. To a certain extent, it was reflected that the dispersion of these three

(a)

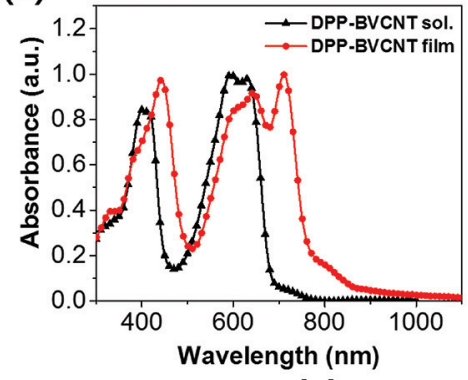

(b)

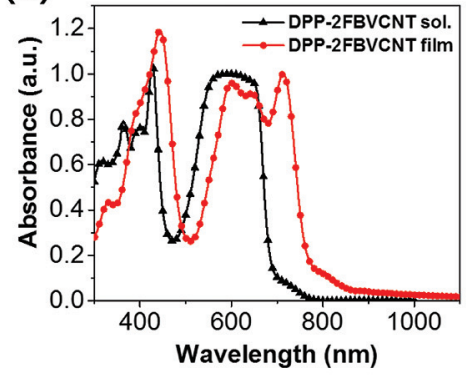

(c)

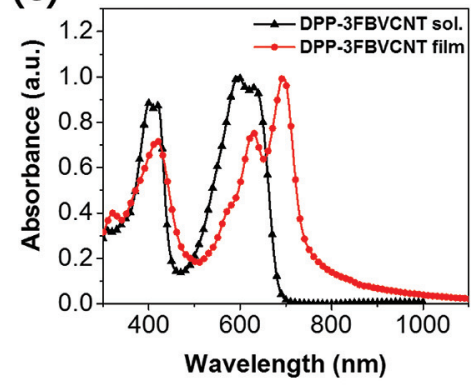

Figure 1 UV-Vis-NIR absorption spectra of small-molecule compounds (a) DPP-BVCNT, (b) DPP-2FBVCNT, and (c) DPP-3FBVCNT in chloroform solutions and thin films. 
materials in chloroform solution and the degree of aggregation after film forming were almost the same.

The peak onsets of the UV-Vis-NIR absorption spectra ( $\left.\lambda_{\text {onset }}\right)$ of these small-molecule compounds' films were used to calculate the optical band gap $E_{g}(\mathrm{opt})$ according to the formula $E_{g}(\mathrm{opt})=1,240 / \lambda_{\text {onset. }}$ The absorption peaks' onsets of DPP-BVCNT, DPP-2FBVCNT, and DPP-3FBVCNT were 786,779 , and $776 \mathrm{~nm}$, respectively. These onset values were put into the above formula to obtain the optical band gaps of the small-molecule compounds as 1.58, 1.59, and $1.60 \mathrm{eV}$ (see Table 1), almost without any significant difference. The above results indicated that for these conjugated compounds, the aggregation-effect difference between in chloroform solution and in film was significant. But both the F-substitution and its position on the donor units of the conjugated backbone had little effect on the absorption spectra and the optical band gaps.

\section{Electrochemical Properties}

We used cyclic voltammetry (CV) to study the electrochemical performance of the three conjugated compounds. In the $\mathrm{CV}$ test, silver/silver chloride $(\mathrm{Ag} / \mathrm{AgCl})$ was used as a reference electrode, trace ferrocene as an internal standard, and a Pt electrode coated with an organic thin film as a working electrode. All measurement data were collected at room temperature under an argon atmosphere. The HOMO and LUMO energy levels of the small-molecule compounds were estimated by using the equations $E_{\mathrm{HOMO}}=-\left(E_{\mathrm{OX}}^{\text {onset }}-E_{F c}\right.$ $+4.80) \mathrm{eV}$ and $E_{\mathrm{LUMO}}=-\left(E_{\mathrm{re}}^{\text {onset }}-E_{\mathrm{FC}}+4.80\right) \mathrm{eV}$ at the starting point of the respective oxidation peaks and reduction peaks. As shown in Figure 2, the initial oxidation/reduction

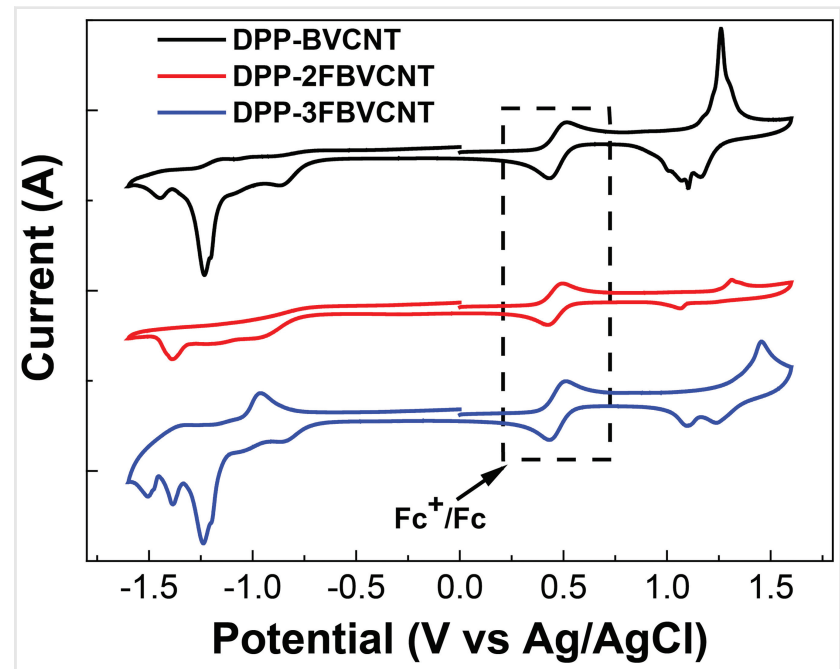

Figure 2 Cyclic voltammetry curves of DPP-DBVCNT-based compounds in an acetonitrile solution containing $0.1 \mathrm{M}$ electrolyte $\mathrm{n}-\mathrm{Bu}_{4} \mathrm{NPF}_{6}$ and trace ferrocene as internal standard. potentials of DPP-BVCNT, DPP-2FBVCNT, and DPP-3FBVCNT were located at $1.11 /-0.73,1.28 /-0.71$, and $1.27 /-0.73 \mathrm{eV}$, respectively. Based on these initial potential values and then calculated according to the above equations, the HOMO/LUMO energy levels of DPP-BVCNT, DPP-2FBVCNT, and DPP-3FBVCNT were obtained as $-5.51 /-3.67,-5.68 /-3.69$, and $-5.67 /-3.67 \mathrm{eV}$ (Table 1 ), respectively. These observations indicated that the introduction of the $\mathrm{F}$ atoms on the donor moieties of the D-A type conjugated backbone could significantly lower the HOMO energy level of these smallmolecule compounds. In addition, from the above oxidation/reduction potential data, we estimated the HOMO-LUMO band gaps $E_{\mathrm{g}}=\left(E_{\mathrm{OX}}^{\text {onset }}-E_{\mathrm{re}}^{\text {onset }}\right)^{21}$ of DPPBVCNT, DPP-2FBVCNT, and DPP-3FBVCNT to be $1.84,1.99$, and $2.00 \mathrm{eV}$, respectively (Figure 2 and Table 1). Among them, the F-substituted conjugated compounds DPP-2FBVCNT and DPP3FBVCNT showed no significant difference in HOMO-LUMO band gaps $E_{\mathrm{g}}$ for each other, but both showed a 0.15-0.16 eV wider band gap compared to that of DPP-BVCNT without the F atoms. It could be seen that the introduction of the $F$ atoms widened the HOMO-LUMO band gap $E_{\mathrm{g}}$ of these conjugated compounds obviously.

From the above observations and calculations of these compounds, the introduction of the $\mathrm{F}$ atoms exhibited an important influence on their electronic structures. It is beneficial to lower the HOMO energy levels and facilitate the HOMO-LUMO band gaps to be widened. The differences between the optical band gaps and the electrochemical band gaps of these compounds are $0.26-0.40 \mathrm{eV}$ within the acceptable experimental error range according to the literature. $^{22}$

\section{Charge Carrier Transport Performance}

To ensure that the relevant n-type or ambipolar fieldeffect performance of organic conjugated small molecules based on DPP-DBVCNT is reflected as accurately as possible, we used the TGBC structure with poly(methyl methacrylate) as the dielectric layer to prepare the OFET devices. These devices were used to study the charge carrier transport performance of the three conjugated compounds DPP-BVCNT, DPP-2FBVCNT, and DPP-3FBVCNT. The TGBC structure can effectively reduce the negative effects of moisture and oxygen, thereby enhancing the ambipolar or n-type charge transport of organic semiconductors. ${ }^{23,24}$ As the devices' performance is largely affected by the thermal annealing process, the films of these compounds were also thermally annealed. Considering that different materials generally need be annealed at different temperatures to achieve their own highest performances, we call the highest performancerelated annealing temperatures as the optimum annealing temperatures. In order to get the optimum annealing temperatures, the performances of the corresponding OFETs 
of each material film were investigated after being annealed at different temperatures in the range of $120-240^{\circ} \mathrm{C}$. The study found that DPP-BVCNT, DPP-2FBVCNT, and DPP-3FBVCNT exhibited different degrees of p-type or ambipolar performances and their optimum annealing temperatures were 240 , 170 , and $140{ }^{\circ} \mathrm{C}$, respectively.

According to the above optimal annealing temperatures, TGBC configurational OFET devices based on the above three organic materials were prepared and the corresponding charge carrier transport performance was detected in air. The OFET devices based on DPP-BVCNT showed a certain degree of p-type OFET performance, while both the DPP-2FBVCNT- and DPP-3FBVCNT-based OFET devices showed obvious ambipolar field-effect performances. Typical transfer and output curves for the OFET devices based on these three small-molecule compounds are shown in Figure 3. All the corresponding parameters are shown in Table 2. According to the listed saturation mobility values of the small-molecule compound-based OFET devices, the p-type material DPPBVCNT showed the highest hole mobility $\left(\mu_{\text {hmax }}\right)$ of $1.57 \times 10^{-3} \mathrm{~cm}^{2} \mathrm{~V}^{-1} \mathrm{~s}^{-1}$. The highest hole/electron mobility $\left(\mu_{\text {hmax }} / \mu_{\text {emax }}\right)$ values of the two ambipolar compounds DPP2FBVCNT and DPP-3FBVCNT were $0.0231 / 0.220$ and $0.0351 / 0.0196 \mathrm{~cm}^{2} \mathrm{~V}^{-1} \mathrm{~s}^{-1}$, respectively. The two ambipolar materials DPP-2FBVCNT and DPP-3FBVCNT exhibited similar hole mobilities but largely different electron mobilities. DPP2FBVCNT exhibited almost an order of magnitude higher electron mobility than that of the DPP-3FBVCNT with one F atom substituted on each of the two inner sides ( $\mu_{\text {emax }}: 0.220$ vs. $0.0196 \mathrm{~cm}^{2} \mathrm{~V}^{-1} \mathrm{~S}^{-1}$ ). DPP-2FBVCNT had one $\mathrm{F}$ atom substituted on each of the two outer sides of the compound, which were on 2-positions of the benzene rings of the two (a)

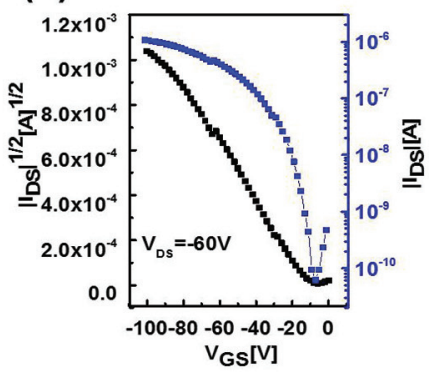

(c)

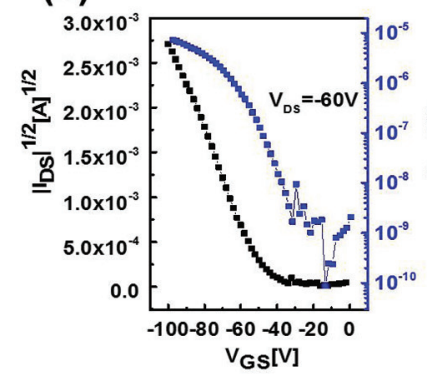

(d)

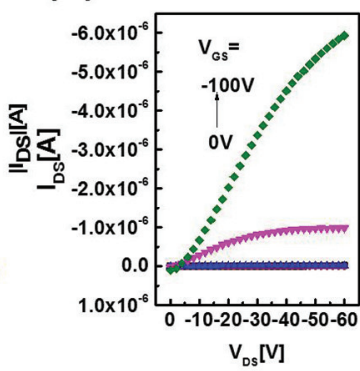

(g)

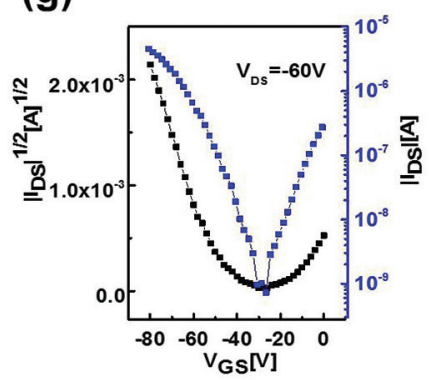

(h)

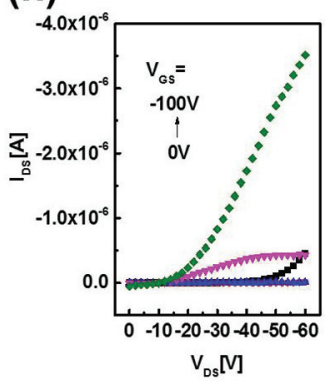

(b)

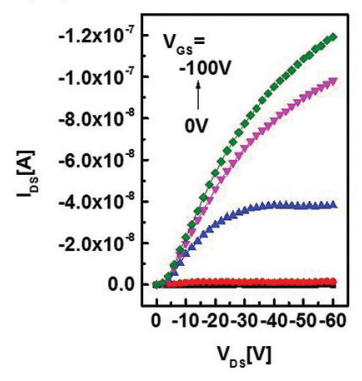

(e)

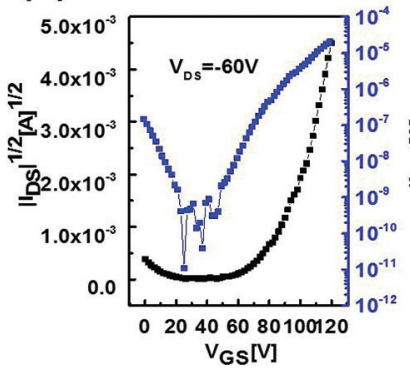

(i)

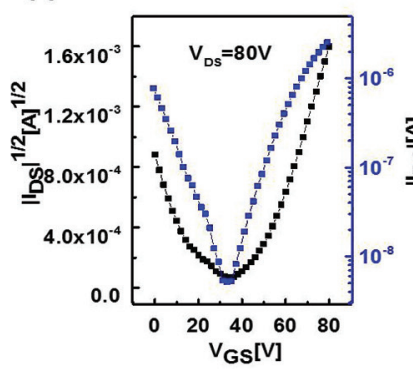

(f)

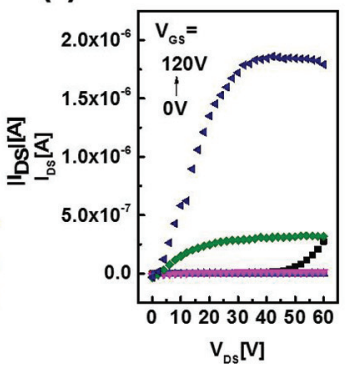

(j)

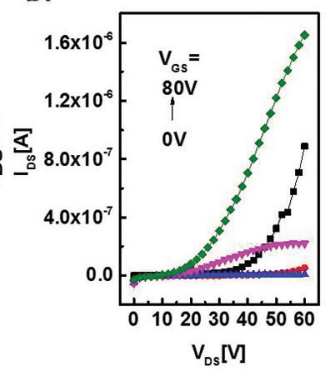

Figure 3 Typical transfer and output curves of OFETs based on the compounds DPP-BVCNT (a-b), DPP-2FBVCNT (c-f), and DPP-3FBVCNT (g-j). 
Table 2 The performances and relative crystalline parameters of the OFET devices with top-gate-bottom-contact (TGBC) configurations

\begin{tabular}{|c|c|c|c|c|c|c|c|c|}
\hline Compd & $\mu_{\text {hmax }}\left(\mathrm{cm}^{2} \mathrm{~V}^{-1} \mathrm{~s}^{-1}\right)$ & $I_{\mathrm{ON}} / \mathrm{I}_{\mathrm{OFF}}$ & $V_{\text {th }}(\mathrm{V})$ & $\mu_{\text {emax }}\left(\mathrm{cm}^{2} \mathrm{~V}^{-1} \mathrm{~s}^{-1}\right)$ & $I_{\mathrm{ON}} / I_{\mathrm{OFF}}$ & $V_{\text {th }}(\mathrm{V})$ & $d-d^{\mathrm{a}}(\AA)$ & $\pi-\Pi^{a}(\AA)$ \\
\hline DPP-BVCNT & $1.57 \times 10^{-3}$ & $10^{4}$ & -11.69 & - & - & - & 24.5 & 3.71 \\
\hline DPP-2FBVCNT & $2.31 \times 10^{-2}$ & $10^{6}$ & -48.05 & $2.20 \times 10^{-1}$ & $10^{7}$ & 82.48 & 24.3 & 3.69 \\
\hline DPP-3FBVCNT & $3.51 \times 10^{-2}$ & $10^{4}-10^{5}$ & -48.62 & $1.96 \times 10^{-2}$ & $10^{3}$ & 48.81 & 23.7 & 3.55 \\
\hline
\end{tabular}

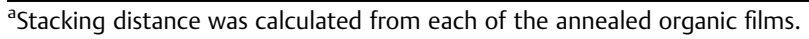

BCNVT donor units and relatively far away from the DPP acceptor unit.

Among these three compounds, the DPP-BVCNTVT-based OFET devices exhibited the lowest on/off current ratios $\left(I_{\text {on }} /\right.$ $\left.I_{\text {off }}\right)$ of $\sim 10^{4}$ and the highest threshold voltage $\left(V_{\text {th }}\right)$ of -11.69 . This might be presumably due to some unintentional doping effects and charge trapping at the compound/oxide and/or the grain boundary interfaces according to the literature reported. ${ }^{25}$ The DPP-3FBVCNT-based devices showed almost similar threshold voltages to those of DPP-2FBVCNT-based devices, maybe because of their nearly similar HOMO/LUMO energy levels, which might be due to the similar conformational lock effects from the F...H bonds in the two compounds according to previous research performed by our group. ${ }^{26,27}$

From the above results, it can be seen that in these DPPDBVCNT-based organic conjugated small molecules, the substitution and the position of the $\mathrm{F}$ atoms introduced into the benzene rings of the donor units had significant effects on the charge carrier transport. It is interesting to note that the introduction of one $\mathrm{F}$ atom into each of the donor benzene rings on both sides of the DPP acceptor unit was beneficial to make the performance of the DPP-BVCNT-based compound be changed from p-type to ambipolar. The compound with one $\mathrm{F}$ atom substituted on each of the outer sides showed a higher electron mobility compared to that of the inner side-substituted one. Meanwhile, the compound with one $\mathrm{F}$ atom substituted on the inner sides exhibited a better balance of ambipolar performances than that of the outer side-substituted one.

\section{Characterization of Thin-Film Microstructure}

The surface morphology and intermolecular aggregation of these three conjugated compounds were mainly analyzed using the height maps obtained via atomic force microscopy (AFM) scanning and the diffraction patterns obtained by a two-dimensional grazing incidence X-ray diffraction (2DGIXRD) test (Figure 4). In regard to the surface microscopic morphology of the organic films, we used the tapping mode AFM to scan the films, and the detection results are shown in Figure 4a-c. The AFM height maps of the DPP-BVCNT, DPP-
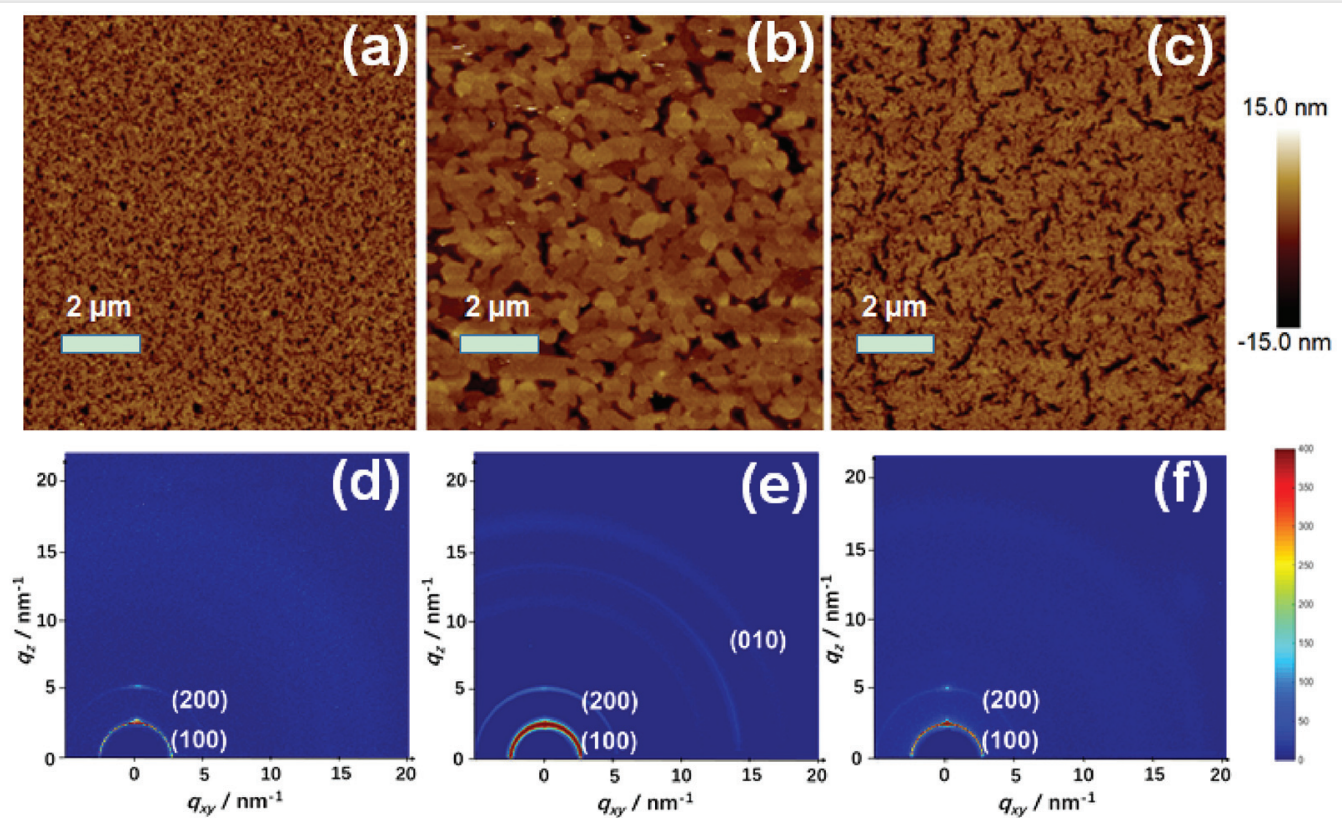

Figure 4 AFM height images (a-c) and 2D-GIXRD diffraction patterns ( $\mathbf{d}-\mathbf{f})$ of the DPP-BVCNT (a, d), DPP-2FBVCNT (b, e), and DPP-3FBVCNT (c, f) thin films after thermal annealing treatment. AFM images are $2 \mu \mathrm{m} \times 2 \mu \mathrm{m}$ in size. 
2FBVCNT, and DPP-3FBVCNT thin films were collected after annealing at their respective optimum annealing temperatures. The DPP-2FBVCNT thin film exhibited the largest crystal grains and good continuity among these three thin films. This morphology was more favorable for charge carrier transport, which was consistent with the fact that its ambipolar field-effect performance was the best among these three materials. Moreover, the DPP-3FBVCNT thin film also showed a certain continuous surface morphology, thus it also exhibited a certain ambipolar field effect.

In order to further understand the relationship between OFET performances and molecular structures, their films were subjected to 2D-GIXRD tests after annealing at their respective optimum annealing temperatures. The obtained $2 D-G I X R D$ results are shown in Figure $4 d-f$. The out-of-plane $\left(q_{z}\right)$ orientation (100) Bragg peaks of $24.5,24.3$, and $23.7 \AA$ correspond to the $d-d$ spacing distances of the compounds DPP-BVCNT, DPP-2FBVCNT, and DPP-3FBVCNT, respectively. In the in-plane $\left(q_{\mathrm{xy}}\right)$ orientation, the $\pi-\pi$ stacking distances of the three compounds' (010) Bragg in-plane peaks are 3.71, 3.69, and 3.55 A for the DPP-BVCNT, DPP-2FBVCNT, and DPP3FBVCNT thin films, respectively. All of the above relevant parameters are listed in Table 2 . The in-plane $\left(q_{\mathrm{xy}}\right)$ and out-ofplane $\left(q_{z}\right)$ direction (010) Bragg peaks provided by the 2DGIXRD diffraction patterns showed that these thin films exhibited a molecular packing pattern of edge-on and face-on mixed orientations relative to the substrates. Interestingly, among these 2D-GIXRD diffraction patterns, DPP-2FBVCNT showed the strongest out-of-plane $\left(q_{\mathrm{z}}\right)$-oriented (h00) diffraction (100) and (200) Bragg peaks, even the obvious (010) Bragg in-plane peak could be directly observed (Figure 4e). This indicates that the DPP-2FBVCN film had the best crystallinity and best orderly layered structure which was consistent with the best field-effect performance among the three small molecules. The 2D-GIXRD patterns corresponding to the other two materials DPP-BVCNT and DPP3FBVCNT (Figure 4d, f) showed relatively weak intensities of the diffraction peaks, which were also consistent with their relatively low field-effect performances.

The above 2D-GIXRD and AFM results (Figure 4) for DPPBVCNT, DPP-2FBVCNT, and DPP-3FBVCNT were combined with the aforementioned optical absorption spectra, electrochemical performance data (Figures 1 and 2, S2, and Table 1), and charge carrier transport performance data (Table 2 and Figure 3), and an analysis of the data was performed. The combined consideration and analysis results showed that the F-substitution and its position on the donor BCNVT units had a significant influence on their electronic structures, the surface morphology of the thin films, the molecular packing mode, and charge carrier mobilities. In other words, the Fsubstitution and its position on the donor units of the conjugated backbones played an important role in regulating the molecular electronic structure, the accumulation between the conjugated frameworks and the intermolecular interac- tion, and thus to some extent in affecting the microstructures of the compound films and charge carrier transport performances. The introduction of the electron-withdrawing $F$ atoms had no obvious influence on the absorption spectroscopy of these small-molecule materials. But to a certain extent, it was beneficial to lower the HOMO energy levels, broaden the HOMO-LUMO energy gaps, improve the molecular aggregation, and remarkably change the performance from p-type to ambipolar especially for the outer side F-substituted compound DPP-2FBVCNT.

\section{Conclusions}

Three D-A type $\pi$-conjugated small-molecule compounds DPP-BVCNT, DPP-2FBVCNT, and DPP-3FBVCNTwere designed and synthesized by adjusting the F-substitution and its position on the BVCNT donor units. All these three compounds were systematically studied for their thermal properties, optical absorption spectra, electrochemical properties, charge carrier transport properties, microscopic arrangement, and surface morphology of the films. They exhibited good thermal stability and good solution dispersion, providing an important guarantee for the solution processing and performance annealing optimization of their OFET devices. The structure-performance relationship indicated that the introduction and the substitution positions of the F atoms showed significant influences on their electronic structures, film surface morphology, molecular packing mode, and charge carrier mobility. The F-substitution could lower the HOMO energy levels and widen HOMO-LUMO band gaps $\left(E_{\mathrm{g}}\right)$ of the DPP-DBVCNT-based compounds. Remarkably, the F atom introduction could change the performance of the DPP-DBVCNT-based compound from p-type to ambipolar. Combined with outer-side-substituted $\mathrm{F}$ atoms, CN groups, and 2-decyltetradecyl side chains, DPP-2FBVCNT showed a more continuous film surface morphology with an orderly layered packing mode, which was more favorable for charge carrier transport than the other two compounds. TGBC-type OFET devices based on DPP-2FBVCNT exhibited the best ambipolar performance with its highest hole/electron mobilities up to $0.0231 / 0.220 \mathrm{~cm}^{2} \mathrm{~V}^{-1} \mathrm{~s}^{-1}$. These findings provided a promising approach to develop good smallmolecule semiconducting materials with high ambipolar performances, good solution processability, and thermal stability.

\section{Experimental Section}

\section{Reagents and Reactions}

All chemicals used in this work were purchased from Innochem, Acros, Alfa Aesar, J\&K Scientific, Sigma-Aldrich, 
etc. The chemicals were in general used without further purification unless otherwise specified. If necessary, toluene and tetrahydrofuran (THF) were freshly distilled using sodium as a water scavenger and using benzophenone as an indicator according to the standard procedures. All Suzuki coupling reactions were operated under the protection of the argon atmosphere in Schlenk reactors.

\section{Measurements and Characterization of Compounds}

${ }^{1} \mathrm{H}$ NMR, ${ }^{13} \mathrm{C}$ NMR, and ${ }^{19} \mathrm{~F}$ NMR spectra of synthetic intermediates and target small molecules were tested and recorded on a Bruker Avance III 400 HD NMR spectrometer or were characterized by using a Bruker Avance III 500WB NMR spectrometer. The reported ${ }^{13} \mathrm{C}$ NMR spectra were not $19 F$ decoupled and hence were reported as empiric enumeration of the observed signals. HRMS measurements of all compounds related were collected on a 9.4T Solarix FTICR mass spectrometer or an APEX II FT-ICR mass spectrometer. TGA measurement data of target small molecules were collected by a PerkinElmer Pyris series TGA8000 thermal analysis system. The UV-Vis-NIR absorption spectra of all synthesized DPP-BVCNT-based small molecules were recorded by using a Hitachi U-3010 spectrophotometer. The CV data obtained on a conventional three-electrode type electrochemistry workstation were used to characterize the electrochemical properties. The three electrodes were respectively as follows: a $\mathrm{Ag} / \mathrm{AgCl}$ electrode as the reference electrode, a platinum wire as the counter electrode, a glassy carbon stick electrode coated with a DPP-BVCNT-based small-molecule thin film layer as the working electrode. A $0.1 \mathrm{M}$ anhydrous solution of tetrabutylammonium hexafluorophosphate in acetonitrile saturated with argon was adopted as the supporting electrolyte. The corresponding oxidative and reductive peaks' onsets of the small molecules were used to estimate the HOMO and LUMO energy levels with the equations: $E_{\text {Homo }}=-\left(E_{\text {ox }}^{\text {onset }}+4.4\right) \mathrm{eV}$ and $E_{\mathrm{LuMO}}=-\left(E_{\mathrm{re}}^{\text {onset }}+4.4\right) \mathrm{eV}$. Thin-film morphologies were analyzed by using a tapping mode Digital Instruments Nanoscope $\mathrm{V}$ atomic force microscope. The data of GIXRD were obtained by illuminating the thin-film samples at $0.2^{\circ}$. All the samples used in the tests of AFM, 2D-GIXRD, and OFET performance analysis were same.

\section{Synthetic Procedure}

The synthetic routes of the conjugated small molecules DPP-BVCNT, DPP-2FBVCNT, and DPP-3FBVCNT are shown in Scheme 1. Intermediate compounds $\mathbf{2 a - 2 c}$ and $\mathbf{3}$ were prepared according to the reported methods. ${ }^{12-19}$

\section{General Preparation Method of the Key BVCNT-Based Intermediates $(2 a-2 c)$}

The intermediates were prepared according to the method reported in literature. ${ }^{19}$ Potassium tert-butoxide $(25.0 \mathrm{mmol})$ was added to anhydrous methanol ( $50 \mathrm{~mL}$ ) and stirred until completely dissolved. After the mixture was cooled to room temperature, 2-(thiophen-2-yl)acetonitrile (25.0 mmol) was added into it, followed by 1 hour of stirring, then one of the compounds 1a-1c $(25.0 \mathrm{mmol})$ was added and the mixture was stirred overnight. The precipitate was filtered to get the filter cake which was further purified by recrystallization from methanol to obtain the corresponding intermediate (2a-2c) as a yellow or white powder (yield: $28-84 \%$ ).

4-BrBVCNT (2a): (white powder, yield: $84 \%$ ). ${ }^{1} \mathrm{H}$ NMR (400 MHz, $\left.\mathrm{CDCl}_{3}, \mathrm{TMS}\right): \delta=7.71-7.68(\mathrm{~m}, 2 \mathrm{H}), 7.58-7.54$ (m, 2H), 7.39-7.38 (m, 1H), 7.33-7.31 (m, 1H), $7.28(\mathrm{~s}, 1 \mathrm{H})$, 7.08-7.05 (m, 1H). ${ }^{13} \mathrm{C}$ NMR (101 MHz, $\left.\mathrm{CDCl}_{3}, \mathrm{TMS}\right)$ : $\delta=138.89, \quad 137.99, \quad 132.27, \quad 132.27, \quad 132.27, \quad 130.46$, 130.46, 128.25, 127.67, 126.65, 124.83, 116.61, 106.80 . HRMS (MALDI): calcd. for $\mathrm{C}_{13} \mathrm{H}_{9} \mathrm{BrNS}[\mathrm{M}+\mathrm{H}]^{+}(289.9639)$; found: 289.9636. HRMS (MALDI): calcd. for $\mathrm{C}_{13} \mathrm{H}_{8} \mathrm{BrNNaS}$ $[\mathrm{M}+\mathrm{Na}]^{+}$(311.9453); found: 311.9456 .

2-F-4-BrBVCNT (2b): (yellow powder, yield: $56 \%$ ). ${ }^{1} \mathrm{H}$ NMR (400 MHz, $\left.\mathrm{CDCl}_{3}, \mathrm{TMS}\right): \delta=8.09(\mathrm{t}, J=8.0 \mathrm{~Hz}, 1 \mathrm{H})$, $7.49(\mathrm{~s}, 1 \mathrm{H}), 7.42-7.38(\mathrm{~m}, 2 \mathrm{H}), 7.36-7.31(\mathrm{~m}, 2 \mathrm{H}), 7.09-7.07$ $(\mathrm{m}, 1 \mathrm{H}) .{ }^{13} \mathrm{C}$ NMR $\left(101 \mathrm{MHz}, \mathrm{CDCl}_{3}, \mathrm{TMS}\right): \delta=161.62$, $159.06,138.71,129.39,129.01,128.24,128.15,128.11$, 128.08, 127.21, 119.68, 116.28, 108.59. ${ }^{19} \mathrm{~F}$ NMR (470 MHz, $\mathrm{CDCl}_{3}, \mathrm{TMS}$ ): $\delta=-111.88$. HRMS (MALDI): calcd. for $\mathrm{C}_{13} \mathrm{H}_{8}$ BrFNS $[\mathrm{M}+\mathrm{H}]^{+}$(307.9539); found: 307.9541 .

3-F-4-BrBVCNT(2c): (yellow powder, yield: $28 \%) .{ }^{1} \mathrm{H}$ NMR (400 MHz, $\left.\mathrm{CDCl}_{3}, \mathrm{TMS}\right): \delta=7.65-7.60(\mathrm{~m}, 2 \mathrm{H}), 7.51-7.48(\mathrm{~m}$, $1 \mathrm{H}), 7.42-7.41(\mathrm{~m}, 1 \mathrm{H}), 7.36-7.34(\mathrm{~m}, 1 \mathrm{H}), 7.26(\mathrm{~s}, 1 \mathrm{H})$, 7.10-7.07 (m, 1H). ${ }^{13} \mathrm{C}$ NMR (101 MHz, $\left.\mathrm{CDCl}_{3}, \mathrm{TMS}\right)$ : $\delta=160.83,157.54,138.50,136.52,134.44,134.11,128.34$, 128.18, 127.09, 125.86, 116.24, 111.53, 108.00. ${ }^{19} \mathrm{~F}$ NMR (470 MHz, $\left.\mathrm{CDCl}_{3}, \mathrm{TMS}\right): \delta=-105.58$. HRMS (MALDI): calcd. for $\mathrm{C}_{13} \mathrm{H}_{8} \mathrm{BrFNS}[\mathrm{M}+\mathrm{H}]^{+}$(307.9539); found: 307.9541 .

\section{General Preparation Procedure of DPP-BVCNT-Based Compounds}

One of the BVCNT-based key intermediates 2a-2c (0.60 mmol), bisborate-DPP (3) $(0.25 \mathrm{mmol}), 2 \mathrm{M}$ aqueous $\mathrm{Na}_{2} \mathrm{CO}_{3}$ solution $(6 \mathrm{~mL})$, and toluene $(20 \mathrm{~mL})$ were successively added to a $50 \mathrm{~mL}$ Schlenk flask. After the flask was strictly charged with $\mathrm{Ar}, \mathrm{Pd}\left(\mathrm{PPh}_{3}\right)_{4}(0.06 \mathrm{mmol})$ and $\mathrm{KF}$ $(0.3 \mathrm{mmol})$ were added quickly. Then the above mixture under an $\mathrm{Ar}$ atmosphere was heated to $110{ }^{\circ} \mathrm{C}$ and stirred at this temperature for 48 hours. The reaction mixture was cooled to room temperature and the catalyst was removed by filtration through a short silica gel pad with the eluent 
ethyl acetate (EA). After washing with water and brine and then dried with $\mathrm{Na}_{2} \mathrm{SO}_{4}$, the combined EA filtrate was concentrated in vacuo. Silica gel chromatography was adopted to purify the above residue with the eluent dichloromethane/petroleum ether and squatting from chloroform/methanol resulted in the target compound as a dark green or blue-black or brown viscous solid.

DPP-BVCNT (yield: 48\%). ${ }^{1} \mathrm{H}$ NMR (500 MHz, $373.2 \mathrm{~K}$, $\left.\mathrm{CDCl}_{2} \mathrm{CDCl}_{2}, \mathrm{TMS}\right): \delta=8.84(\mathrm{~d}, J=4.1 \mathrm{~Hz}, 2 \mathrm{H}), 7.91(\mathrm{~d}$, $J=8.3 \mathrm{~Hz}, 4 \mathrm{H}), 7.77(\mathrm{~d}, J=8.3 \mathrm{~Hz}, 4 \mathrm{H}), 7.55(\mathrm{~d}, J=4.1 \mathrm{~Hz}$, $2 \mathrm{H}), 7.43(\mathrm{~d}, J=3.5 \mathrm{~Hz}, 2 \mathrm{H}), 7.40-7.31(\mathrm{~m}, 4 \mathrm{H}), 7.16-7.05(\mathrm{~m}$, $2 \mathrm{H}), 4.07(\mathrm{~d}, J=7.6 \mathrm{~Hz}, 4 \mathrm{H}), 2.02(\mathrm{~s}, 2 \mathrm{H}), 1.39-1.23(\mathrm{~m}, 80 \mathrm{H})$, 0.92-0.84 (m, 12H, $\left.-\mathrm{CH}_{3}\right) .{ }^{13} \mathrm{C}$ NMR $(126 \mathrm{MHz}, 373.2 \mathrm{~K}$, $\left.\mathrm{CDCl}_{2} \mathrm{CDCl}_{2}, \mathrm{TMS}\right): \delta=161.72,148.20,139.88,139.29$, $138.39,136.31,135.13,133.83,130.13,129.90,128.23$, $127.42,126.72,126.50,125.42,116.67,109.23,106.80$, 46.75, 38.12, 31.83, 30.01, 29.62, 29.58, 29.51, 29.24, 26.58, 22.56, 13.93. HRMS (MALDI): calcd. for $\mathrm{C}_{88} \mathrm{H}_{119} \mathrm{~N}_{4} \mathrm{O}_{2} \mathrm{~S}_{4}[\mathrm{M}+$ $\mathrm{H}^{+}$(1391.8210); found: 1391.8199. Elemental anal. calcd. for $\mathrm{C}_{88} \mathrm{H}_{118} \mathrm{~N}_{4} \mathrm{O}_{2} \mathrm{~S}_{4}:$ C 75.92, H 8.54, N 4.02. Found: C 77.45, H 8.41, N 4.20 .

DPP-2FBVCNT (yield: 56\%): ${ }^{1} \mathrm{H}$ NMR (500 MHz, $373.2 \mathrm{~K}$, $\left.\mathrm{CDCl}_{2} \mathrm{CDCl}_{2}, \mathrm{TMS}\right): \delta=8.72(\mathrm{~d}, J=4.0 \mathrm{~Hz}, 2 \mathrm{H}), 8.19(\mathrm{t}$, $J=8.0 \mathrm{~Hz}, 2 \mathrm{H}), 7.50(\mathrm{~d}, J=10.0 \mathrm{~Hz}, 4 \mathrm{H}), 7.44(\mathrm{~d}, J=4.0 \mathrm{~Hz}$, $2 \mathrm{H}), 7.36(\mathrm{t}, J=3.5 \mathrm{~Hz}, 4 \mathrm{H}), 7.28(\mathrm{~d}, J=5.0 \mathrm{~Hz}, 2 \mathrm{H}), 7.01(\mathrm{t}$, $J=4.0 \mathrm{~Hz}, 2 \mathrm{H}), 3.97$ (d, $J=7.5 \mathrm{~Hz}, 4 \mathrm{H}), 1.91(\mathrm{~m}, 2 \mathrm{H})$, 1.32-1.16 (m, 80H), 0.79-0.77 (m, 12H, $\left.-\mathrm{CH}_{3}\right) .{ }^{13} \mathrm{C}$ NMR (126 MHz, $373.2 \mathrm{~K}, \mathrm{CDCl}_{2} \mathrm{CDCl}_{2}$, TMS): $\delta=162.12,161.63$, $160.10,146.79,139.79,139.14,137.07,137.01,136.29$, $130.64,129.78,128.98,128.27,127.83,127.26,125.97$, $122.18,116.37,113.02,112.83,109.44,108.48,46.75,38.14$, $31.85,31.82,30.01,29.58,29.55,29.51,29.23,26.58,22.56$, 13.93. ${ }^{19} \mathrm{~F}$ NMR (470 MHz, $\left.373.2 \mathrm{~K}, \mathrm{CDCl}_{2} \mathrm{CDCl}_{2}, \mathrm{TMS}\right)$ : $\delta=-132.74$. HRMS (MALDI): calcd. for $\mathrm{C}_{88} \mathrm{H}_{117} \mathrm{~F}_{2} \mathrm{~N}_{4} \mathrm{O}_{2} \mathrm{~S}_{4}$ $[\mathrm{M}+\mathrm{H}]^{+}$(1427.8022); found: 1427.8021. Elemental anal. calcd. for $\mathrm{C}_{88} \mathrm{H}_{116} \mathrm{~F}_{2} \mathrm{~N}_{4} \mathrm{O}_{2} \mathrm{~S}_{4}$ : C 74.01, $\mathrm{H}$ 8.19, N 3.92. Found: C 73.51, H 8.20, N 3.84.

DPP-3FBVCNT (yield: 36\%): ${ }^{1} \mathrm{H}$ NMR (500 MHz, $373.2 \mathrm{~K}$, $\left.\mathrm{CDCl}_{2} \mathrm{CDCl}_{2}, \mathrm{TMS}\right): \delta=8.78(\mathrm{~d}, J=4.0 \mathrm{~Hz}, 2 \mathrm{H}), 7.70(\mathrm{t}$, $J=7.5 \mathrm{~Hz}, 2 \mathrm{H}), 7.62(\mathrm{~d}, J=7.5 \mathrm{~Hz}, 6 \mathrm{H}), 7.35(\mathrm{~d}, J=3.5 \mathrm{~Hz}$, $2 \mathrm{H}), 7.28(\mathrm{~d}, J=5.0 \mathrm{~Hz}, 2 \mathrm{H}), 7.22(\mathrm{~s}, 2 \mathrm{H}), 7.02(\mathrm{t}, J=3.5 \mathrm{~Hz}$, $2 \mathrm{H}), 3.98(\mathrm{~d}, J=7.5 \mathrm{~Hz}, 4 \mathrm{H}), 1.91(\mathrm{~m}, 2 \mathrm{H}), 1.32-1.16$ $(\mathrm{m}, 80 \mathrm{H}), 0.78-0.77\left(\mathrm{~m}, 12 \mathrm{H},-\mathrm{CH}_{3}\right) .{ }^{13} \mathrm{C}$ NMR $(126 \mathrm{MHz}$, $\left.373.2 \mathrm{~K}, \mathrm{CDCl}_{2} \mathrm{CDCl}_{2}, \mathrm{TMS}\right): \delta=161.72,160.16,158.15$, $141.24,139.97,138.94,136.77,135.71,135.13,131.05$, $128.82,128.32,128.19,127.90,127.18,125.50,116.78$, 116.59, 116.26, 109.49, 108.05, 46.83, 38.21, 31.85, 30.00, $29.60,29.56,29.47,29.21,26.56,22.54,13.88 .{ }^{19} \mathrm{~F}$ NMR (470 MHz, $373.2 \mathrm{~K}, \mathrm{CDCl}_{2} \mathrm{CDCl}_{2}$, TMS): $\delta=-130.17$. HRMS (MALDI): calcd. for $\mathrm{C}_{88} \mathrm{H}_{117} \mathrm{~F}_{2} \mathrm{~N}_{4} \mathrm{O}_{2} \mathrm{~S}_{4}[\mathrm{M}+\mathrm{H}]^{+}(1427.8022)$; found: 1427.8013. Elemental anal. calcd. for $\mathrm{C}_{88} \mathrm{H}_{116} \mathrm{~F}_{2} \mathrm{~N}_{4} \mathrm{O}_{2} \mathrm{~S}_{4}$ : C 74.01, $\mathrm{H}$ 8.19, N 3.92. Found: C 73.59, H 8.30, N 3.74.

\section{Funding Information}

This study was funded by the National Key Research and Development Program of China (2016YFB0401100, 2017YFA0204703) and the National Natural Science Foundation of China (21673258, 21774134, and 51773016)

\section{Acknowledgement}

The authors are grateful for the help from the scientists at the 1W1A Station of Beijing Synchrotron Radiation Facility (BSRF) and BL14B1 Station of Shanghai Synchrotron Radiation Facility (SSRF) during the GXRD tests.

\section{Supporting Information}

Supporting information for this article is available online at https://doi.org/10.1055/s-0039-3402057.

\section{References}

(1) Hu, Y.; Rengert, Z. D.; McDowell, C.; Ford, M. J.; Wang, M.; Karki, A.; Lill, A. T.; Bazan, G. C.; Nguyen, T. Q. ACS Nano 2018, $12,3938$.

(2) Khim, D.; Han, H.; Baeg, K. J.; Kim, J.; Kwak, S. W.; Kim, D. Y.; Noh, Y. Y. Adv. Mater. 2013, 25, 4302.

(3) Baeg, K. J.; Caironi, M.; Noh, Y. Y. Adv. Mater. 2013, 25, 4210.

(4) Ghosh, S.; Raveendran, R.; Saeki, A.; Seki, S.; Namboothiry, M.; Ajayaghosh, A. ACS Appl. Mater. Interfaces 2019, 11, 1088.

(5) Song, X.; Gasparini, N.; Nahid, M. M.; Chen, H.; Macphee, S. M.; Zhang, W.; Norman, V.; Zhu, C.; Bryant, D.; Ade, H.; McCulloch, I.; Baran, D. Adv. Funct. Mater. 2018, 28, 1802895.

(6) He, T.; Leowanawat, P.; Burschka, C.; Stepanenko, V.; Stolte, M.; Wurthner, F. Adv. Mater. 2018, 30, 1804032.

(7) Lim, B.; Sun, H.; Lee, J.; Noh, Y. Y. Sci. Rep. 2017, 7, 164.

(8) Mei, J.; Kim, D. H.; Ayzner, A. L.; Toney, M. F.; Bao, Z. J. Am. Chem. Soc. 2011, 133, 20130.

(9) Zhang, W.; Chen, Z.; Mao, Z.; Gao, D.; Wei, C.; Lin, Z.; Huang, J.; Wang, L.; Yu, G. Dyes Pigm. 2018, 149, 149.

(10) Lee, J.; Han, A. R.; Kim, J.; Kim, Y.; Oh, J. H.; Yang, C. J. Am. Chem. Soc. 2012, 134, 20713.

(11) Yao, J.; Yu, C.; Liu, Z.; Luo, H.; Yang, Y.; Zhang, G.; Zhang, D. J. Am. Chem. Soc. 2016, 138, 173.

(12) Shi, K.; Zhang, W.; Wei, C.; Lin, Z.; Liu, X.; Yu, G. J. Polym. Sci. Part A: Polym. Chem. 2018, 56, 1012.

(13) Conboy, G.; Taylor, R. G. D.; Findlay, N. J.; Kanibolotsky, A. L.; Inigo, A. R.; Ghosh, S. S.; Ebenhoch, B.; Jagadamma, L. K.; Thalluri, G. K. V. V.; Sajjad, M. T.; Samuel, I. D. W.; Skabara, P. J. J. Mater. Chem. C. 2017, 5, 11927.

(14) Zhang, W.; Mao, Z.; Zheng, N.; Zou, J.; Wang, L.; Wei, C.; Huang, J.; Gao, D.; Yu, G. J. Mater. Chem. C. 2016, 4, 9266.

(15) Bürckstümmer, H.; Weissenstein, A.; Bialas, D.; Würthner, F. J. Org. Chem. 2011, 76, 2426.

(16) Lee, J.; Cho, S.; Seo, J. H.; Anant, P.; Jacob, J.; Yang, C. J. Mater. Chem. 2012, 22, 1504. 
(17) Cortizo-Lacalle, D.; Arumugam, S.; Elmasly, S. E. T.; Kanibolotsky, A. L.; Findlay, N. J.; Inigo, A. R.; Skabara, P. J. Mater. Chem. 2012, 22,11310

(18) Lee, J.; Han, A. R.; Hong, J.; Seo, J. H.; Oh, J. H.; Yang, C. Adv. Funct. Mater. 2012, 22, 4128

(19) Yun, H. J.; Kang, S. J.; Xu, Y.; Kim, S. O.; Kim, Y. H.; Noh, Y. Y.; Kwon, S. K. Adv. Mater. 2014, 26, 7300.

(20) Li, Y.; Singh, S. P.; Sonar, P. Adv. Mater. 2010, 22, 4862.

(21) Cui, Y.; Zhang, X.; Jenekhe, S. A. Macromolecules 1999, 32, 3824.

(22) Gao, D.; Chen, Z.; Mao, Z.; Huang, J.; Zhang, W.; Li, D.; Yu, G. RSC Adv. 2016, 6, 78008.
(23) Yan, H.; Chen, Z.; Zheng, Y.; Newman, C.; Quinn, J. R.; Dotz, F.; Kastler, M.; Facchetti, A. Nature 2009, 457, 679.

(24) Chen, H.; Guo, Y.; Mao, Z.; Yu, G.; Huang, J.; Zhao, Y.; Liu, Y. Chem. Mater. 2013, 25, 3589.

(25) Jo, G.; Jeong, J. W.; Choi, S.; Kim, H.; Park, J.; Jung, J.; Chang, M. ACS Appl. Mater. Interfaces 2019, 11, 1135.

(26) Zhang, W.; Shi, K.; Huang, J.; Gao, D.; Mao, Z.; Li, D.; Yu, G. Macromolecules 2016, 49, 2582.

(27) Lin, Z.; Liu, X.; Zhang, W.; Huang, J.; Wang, Q.; Shi, K.; Chen, Z.; Zhou, Y.; Wang, L.; Yu, G. Macromolecules 2018, 51, 966. 